\title{
Treatment of the Adult Retina with Microglia-suppressing Factors Retards Axotomy-induced Neuronal Degradation and Enhances Axonal Regeneration in vivo and in vitro
}

\author{
Solon Thanos, Jörg Mey, and Monika Wild \\ Research Laboratory, Department of Ophthalmology, University of Tübingen, School of Medicine, D 7400 Tübingen, \\ Germany
}

To monitor the cascade of events initiated by injury of adult neurons, and to explore whether and how neighboring microglial cells contribute to the degradation of lesioned neurons, axotomy-induced ganglion cell degeneration was investigated in adult rats. Suppression of macrophage and microglia activity during the weeks following transection of the optic nerve was performed with the immunoglobulinderived tripeptide Thr-Lys-Pro, which is a macrophage inhibitory factor (MIF) and retards the activity of cells of monocytic origin. Single or repeated injection of MIF into the vitreous body during and after transection of the optic nerve resulted in significant retardation of axotomy-induced ganglion cell degradation in the retina as detected by specific labeling with the retrogradely transported fluorescent dye 4Di-10ASP. MIF specifically altered the morphology of labeled microglial cells from a ramified to an oval, less ramified shape, indicating that these cells were targets of its activity. Injection of the tetrapeptide macrophage stimulating factor, also known as tuftsin (Thr-Lys-Pro-Arg), revealed effects opposite to those described for the MIF: it increased the number of labeled microglial cells and enhanced the devastating effects of axotomy on ganglion cells. The viability of rescued ganglion cells in retinas treated with the various drugs was assessed both in vivo and in vitro. (1) Intravitreal injection of MIF to prevent degradation of neurons combined with transplantation of autologous peripheral nerve grafts, which facilitate regrowth of the transected neurites, revealed that significantly more ganglion cells contributed to axonal regeneration $(17.1 \%)$ than in untreated controls $(9.5 \%) .(2)$ Explantation of retinas that were pretreated with MIF in situ revealed higher incidence of axonal outgrowth in organ cultures than untreated control explants or retinas treated with either the basic fibroblast growth factor or brain-derived neurotrophic factor. The present results demonstrate that axotomy initializes a cascade of microglia-mediated autodestructive retinal responses, which culminate in degradation of

\footnotetext{
Received Mar. 31, 1992; revised July 16, 1992; accepted July 27, 1992.

We thank Dr. Y. A. Barde for providing the BDNF. Dr. C. Müller contributed with helpful comments on the manuscript and $\mathrm{C}$. Pavlidis with discussions during preparation of the work. The work was supported by the Deutsche Forschungsgemeinschaft (Grants Th 386 2-2 and 3-1) to S.T.

Correspondence should be addressed to S. Thanos, Research Laboratory, Department of Ophthalmology, University of Tübingen, School of Medicine, Schleichstrasse 12, D 7400 Tübingen, Germany.

Copyright (c) 1993 Society for Neuroscience $0270-6474 / 93 / 130455-12 \$ 05.00 / 0$
}

"sick," but obviously viable neurons. We postulate that the retinal microglial system has a key role in recognizing and eliminating severed neurons.

[Key words: rat retina, axotomy, axonal regeneration, nerve grafts, microglia, tuftsin, macrophage inhibitory peptide, immunosuppression, fluorescent dyes]

Observations concerning the regressive consequences of injury to the CNS, especially to the spinal cord and to the retina of higher vertebrates, can be traced back to the early decades of the century (Ramon y Cajal, 1928; James, 1933). In accordance with these observations, which were later confirmed, early responses to injury are followed by delayed autodestructive events such as phospholipid hydrolysis (polyunsaturated fatty acids, eicosanoids, and free radicals), release of neuropeptides, monoamines, and amino acids. These factors sccm to form an intcractive cascade that leads to membrane alteration and death of the cells (review by Faden and Salzmann, 1992). In the paradigm of the present study, the retrograde retinal ganglion cell degeneration commences a few days after intraorbital transection of the optic nerve and progresses during the weeks and months following the axotomy, finally resulting in depletion of the retinal ganglion cell layer (GCL) (Grafstein and Ingoglia, 1982; Barron et al., 1986; Thanos, 1988; Villegas-Perez et al., 1988; Carmignoto et al., 1989).

Several hypotheses regarding the mechanisms of the responses to injury provide the theoretical basis for evaluating different interventions in the cascades of cell destruction. The failure of lesioned ganglion cells to regrow their axons within the distal portion of the optic nerve is assumed to be caused by the presence of differentiated oligodendrocytes, whose myelin exerts inhibiting influences both on embryonic (Schwab and Caroni, 1988) and on adult ganglion cell axons (Vanselow et al., 1990). In addition to the inhibiting environment, a lack of growthsupporting agents within the optic nerve (Ramon y Cajal, 1928) has been assumed to determine the fate of lesioned neurons, namely, the progressive degeneration. External neurotrophic influences introduced by the apposition of peripheral nerve segments at the time of severing the optic nerve could rescue some ganglion cells. These cells can then regenerate their axons into growth-permitting peripheral nerve transplants (Vidal-Sanz et al., 1987, 1991; Villegas-Perez et al., 1988; Carter et al., 1989). Factors released from peripheral nerves also support regrowth of axons in cultured retinal explants (Thanos et al., 1989). The responsiveness of lesioned ganglion cells to external adminis- 
tration of NGF during the first weeks after lesion (Carmignoto et al., 1989) is in accordance with all previous observations that asssume that epigenetic influences can regulate the quantity of neurons that survive axotomy.

The limited success achieved with external application of neurotrophic factors points to the fact that the cascade of autodestruction after injury is still largely unknown. The cellular events that are initiated by axotomy in the CNS therefore deserve further exploration. Intervention into autodestructive responses of ganglion cells and the responses of their glial environment to traumatic injury may provide a persistent increase in the numbers of neurons that can then be recruited to regrow and reconnect their axons. The investigation of the entire local inflammatory response within the retina is therefore of crucial importance to understand the mechanisms of lesion-induced cell death, a prerequisite for therapeutical intervention. Besides the macroglia (astrocytes and the Müller's glia), candidates to be involved in the process of destruction are resident retinal microglial cells, which are the third major population of cells within the retina of mammals (del Rio-Hortega, 1932; Cammermeyer, 1970), and also peripheral macrophages infiltrating the tissuc as a response to injury (Schnitzer and Scherer, 1990; Milligan et al., 1992).

Microglial cells are localized in various areas of the developing adult and lesioned CNS (Cammermeyer, 1970; Perry and Gordon, 1988; Giulian et al., 1989; Streit et al., 1989; Ling et al., 1990; Schnitzer and Scherer, 1990; Thanos, 1991). The function of brain and retinal microglia in the repair process at the sites of injuries is not well defined, although several lines of evidence support the view that these cells are responsible for the immune response and phagocytosis (for reviews, see Perry and Gordon, 1988; Giulian, 1990). Inhibitors of microglia and macrophages like chloroquine and colchicine reduced the numbers of microglial cells after stroke and trauma, retarded astrogliosis, and improved the survival of neurons (Giulian, 1990). Observations based on the temporal relation of the microglia to neuronal cell death in the lesioned adult rabbit and rat retina (Schnitzer and Scherer, 1990; Thanos, 1991) have postulated a relationship of microglia to the dying cells. Phagocytosis-dependent labeling of retinal microglial cells with the membranophilic carbocyanine dyes 4Di-10ASP, and to lesser extent with DiI, illustrated that, indeed, these cells ingest debris of axotomized ganglion cells (Thanos, 1991; Thanos et al., 1992). Suppression of the microglial cells with externally applied inhibitors of proteases and subsequent retardation of the ganglion cell degeneration suggested that the microglial cells may be responsible for recognizing and degrading axotomized ganglion cells (Thanos, 1991). In accordance with these observations, further experimental stimulation or inhibition of microglial metabolic activity should also modulate the progression of neuronal degradation in the retina. Candidates for a stimulation of microglial cells are oligopeptides of the tuftsin family, which are known to stimulate cells derived from bone marrow including microglial cells, which are also of monocytic origin (Tzehoval et al., 1978; Fridkin and Najjar, 1989; Naim et al., 1989; Plata-Salaman, 1989; Spirer et al., 1989; Bump et al., 1990; Kraus-Berthier et al., 1991). Macrophage-stimulating tuftsin itself is a tetrapeptide (Thr-Lys-ProArg) and is located in the $F_{c}$ region of human $\operatorname{IgG}$ between amino acids 289 and 292 of the $\mathrm{CH} 2$ domain (Naim et al., 1989; Bump et al., 1990). A candidate for suppression of macrophages and microglial cells is the so-called macrophage inhibitory tripeptide ( $\mathrm{Thr}^{289}$-Lys-Pro ${ }^{291}$ ), also derived from the second constant domain of the human immunoglobulin G (Auriault et al.,
1983). This tripeptide counteracts the effects of tuftsin and acts to a number of cells of mononuclear origin (for literature review, see Plata-Salaman, 1989).

The breakdown of the ganglion cell membrane function and structure seems to be the core consequence of axotomy (Faden and Salzman, 1992). It is proposed in the present work that microglial cells, as part of the intraretinal anti-inflammatory system, may be directly involved in the recognition and destruction of axotomized, but presumably viable ganglion cells. The investigation therefore monitored whether pharmacological suppression of the microglial cells can influence the speed of neuronal degeneration and, consequently, whether treatment of the microglial metabolism can enhance the numbers of ganglion cells that regenerate their neurites. The experimental test of the hypothesis was transection of the optic nerves in adult rats beyond the eye cup and examination of ganglion cell survival and regeneration of axons. It is shown here that substantial numbers of vital ganglion cells can be rescued and will express regenerative capacities. The effects of the microglia-suppressing factor in retinal explants are compared with the effects of neurotrophic factors like basic fibroblast growth factor (bFGF) (Sievers et al., 1987) and brain-derived neurotrophic factor (BDNF) (Barde et al., 1982). In the same retinas, significant delay in the specific, phagocytosis-dependent transcellular labeling of microglia indicated that the macrophage-inhibitory peptide may specifically interact with the function of microglial cells and prevent degradation of axotomized ganglion cells.

\section{Materials and Methods}

Surgery at the optic nerve, injection and staining procedures. Adult female rats from the Sprague-Dawley strain weighing 200-230 gm were used for the present study. Under intraperitoneal chloral hydrate anesthesia $(0.42 \mathrm{mg} / \mathrm{kg}$ body weight), the left optic nerve was intraorbitally exposed and, after longitudinal incision of its meningeal sheath, the nerve was completely transected without affecting the retinal blood supply. In 100 rats, solid crystals $(0.2-0.4 \mathrm{~mm}$ in diameter) of the fluorescent styryl dye 4Di-10ASP $[1]^{291} ; N$-4-(4-didecylaminostyryl)- $N$-methylpyridinium iodide; Molecular Probes, Eugene, Oregon] were deposited immediately after transection onto the ocular stump of the optic nerve, to label the retinal ganglion cells retrogradely before they undergo degeneration under the various experimental conditions defined below. At same time, $10 \mu \mathrm{l}$ of anterior chamber fluid was retrieved from the anterior eye chamber with a pulled glass capillary penetrating the cornea. The volume of about $10 \mu$ was then replaced by injecting either of the substances listed below into the posterior chamber with a pulled glass capillary penetrating the sclera. The rats were divided into the following groups (see Tables 1 and 2). Animals of group 1 (12 rats) received 10 $\mu \mathrm{l}$ of a freshly prepared solution containing $500 \mu_{\mathrm{M}}$ of macrophage inhibitory factor (MIF; Thr-Lys-Pro; Sigma; Auriault et al., 1983). Animals of group 2 (12 rats) received repeated injections of MIF every 14 d (total of three injections). Rats of group $3(n=12)$ received $10 \mu$ l of a solution containing $100 \mu \mathrm{M}$ of the tetrapeptide tuftsin (Thr-Lys-ProArg; Sigma), which is known to stimulate macrophages and monocytes in various tissues, thus called macrophage stimulating factor (MSF) (Tzehoval et al., 1978; Fridkin and Najjar, 1989; Naim et al., 1989; Wagle et al., 1989; Kraus-Berthier et al., 1991). A control group ( $n=$ 24) was subjected to optic nerve transection and received 4Di-10ASP into the optic nerve stump but no injection of drugs. Twelve of them were used to determine the normal course of retrograde ganglion cell degeneration and microglial labeling; the others received one intravitreal injection of $10 \mu \mathrm{l}$ phosphate buffer (12 rats). In a last group of four animals, MIF was injected into the vitreous body 4 weeks after optic nerve transection and labeling to monitor its effects on the morphology of the prelabeled microglial cells.

Following survival times of $3 \mathrm{~d}$ to 12 months depending on the scope of the experiment, the rats were killed with a lethal dose of chloral hydrate. After intracardial perfusion with phosphate buffered saline, the animals were perfused with $200 \mathrm{ml}$ of aqueous $4 \%$ paraformaldehyde for fixation and their retinas were dissected, incised into four quadrants, and flat-mounted on filters with the nerve fiber layer upward. Exami- 
Table 1. Retinal ganglion cell survival in vivo (optic nerve

transection and grafting of sciatic nerve segment in situ)

\begin{tabular}{|c|c|}
\hline $\begin{array}{l}\text { Number } \\
\text { of } \\
\text { animals }\end{array}$ & Intravitreal injection \\
\hline 12 & Group 1: $10 \mu \mathrm{l} \mathrm{MIF}, 500 \mu \mathrm{M}$; once, during axotomy \\
\hline 12 & $\begin{array}{l}\text { Group 2: } 10 \mu \mathrm{lMIF}, 500 \mu \mathrm{M} \text {; three times, during } \\
\text { axotomy, after } 14 \mathrm{~d} \text {, and after } 28 \mathrm{~d}\end{array}$ \\
\hline 12 & Group 3: $10 \mu \mathrm{l} \mathrm{MSF}, 100 \mu \mathrm{M}$; once, during axotomy \\
\hline 12 & Controls: no injection \\
\hline 12 & Controls: $10 \mu \mathrm{l}$ PBS, $0.1 \mathrm{M}$; once, during axotomy \\
\hline 4 & $\begin{array}{l}\text { Controls: } 10 \mu 1 \mathrm{MIF}, 500 \mu \mathrm{M} \text {; once, } 4 \text { weeks after } \\
\text { axotomy and labeling }\end{array}$ \\
\hline
\end{tabular}

nation occurred with the fluorescence microscope equipped with filters for fluorescein, as Di-10ASP emits green-yellowish fluorescence.

Transplantation of peripheral nerve pieces. To prove whether pharmacological treatment of the axotomized retinas results in rescue of viable ganglion cells, the regenerative propensity of the ganglion cells was monitored in rats that received peripheral nerve transplants and suppression of microglial activity. For this, eight animals received optic nerve transection, injection of MIF as mentioned above, and transplantation of an autologous piece of the sciatic nerve (Vidal-Sanz et al., 1987). The peripheral nerve graft was revised in its epicranial segment 4 weeks after grafting and the ganglion cells whose axons had grown into the graft were retrogradely filled with the fluorescent dye 4Di-10ASP from a distance of about $12-14 \mathrm{~mm}$ beyond the optic nerve stump. The retinas of these animals were examined as whole-mounts $4 \mathrm{~d}$ after deposition of the dye into the graft.

Explanation of retinal stripes. Under chloral hydrate anesthesia, the left oplic nerve of 32 rats was surgically exposed and crushed within its intraorbital segment with a jeweler's forceps, to produce a conditioning lesion that has beneficial effects on the regenerative response of ganglion cells (Thanos et al., 1989). The rats were divided into six groups (Tables 1 and 2). Each experimental group received $10 \mu \mathrm{l}$ of each one of the agents listed above-either as intravitreal injection during axotomy, or as supplement to the culture medium after the explantation, which was $6 \mathrm{~d}$ after axotomy. Animals received one of the following: fibroblast growth factor $(10 \mu \mathrm{g} / \mathrm{ml} \mathrm{bFGF}, n=4)$ during explantation; MIF during axotomy $(n=4)$ or during explantation $(n=4)$; brain-derived neurotrophic factor (BDNF) during explantation $(n=4)$; combined injection of MIF during axotomy and addition of BDNF during explantation ( $n$ $=4$ ); or explant after axotomy but no injection $(n=4)$. Six days after optic nerve transection, the retinas of animals with injected eyes and these of the control group were dissected under sterile conditions and were used to produce organ cultures in a chemically defined medium devoid of serum and growth factors according to the technique of Thanos et al. (1989). Each retina was divided into eight segments centered at the optic nerve head, which were then explanted on petriperm dishes (Heraeus, Hanan, Germany) coated with polylysine (MW 370,000$410,000 \mathrm{Da}$; Boehringer; $200 \mu \mathrm{g} / \mathrm{ml}$, overnight at $37^{\circ} \mathrm{C}$ ) and laminin (Bethesda Research Labs; $20 \mu \mathrm{g} / \mathrm{ml}, 1 \mathrm{hr}$ at $37^{\circ} \mathrm{C}$ ) with the ganglion cell layer facing the substrate. For examining the effects of the various substances injected in situ, the explants obtained from all retinas were examined for axonal growth with an inverted phase-contrast microscope after $2 \mathrm{~d}$ in culture. Numbers of fibers were measured at a distance of about $200 \mu \mathrm{m}$ from the edge of each explant (Thanos et al., 1989). Averaged numbers of axons from each group of explants were compared by means of the Student's $t$ test.

Morphometry. The retinas obtained after optic nerve transection and subsequent degeneration in situ were viewed as whole-mounts. Fluorescent ganglion cells and microglia were observed through the fluorescein filter. For quantification of the ganglion and microglial cells, each retina was divided into three concentric areas with radii of about $1 \mathrm{~mm}$ (central), $2 \mathrm{~mm}$ (middle), and more than $2 \mathrm{~mm}$ (peripheral), from the center of the optic nerve head as seen in the whole-mounted retina. Ganglion cell and microglia densities were determined in each concentric field by measuring $30-40$ randomly distributed microscope fields in each quadrant with the $20 \times$ lens. The data were averaged for each field and then to obtain densities of ganglion and microglial cells across
Table 2. Neuritogenesis of retinal ganglion cells in vitro (explanation of retinal segments $6 \mathrm{~d}$ after optic nerve crush)

\begin{tabular}{lll}
$\begin{array}{l}\text { Number of } \\
\text { animals }\end{array}$ & $\begin{array}{l}\text { Intravitreal injection } \\
\text { during optic nerve crush }\end{array}$ & $\begin{array}{l}\text { As supplement to the } \\
\text { culture medium }\end{array}$ \\
\hline 4 & - & bFGF, 10 $\mu \mathrm{g} / \mathrm{ml}$ \\
4 & $10 \mu \mathrm{l} \mathrm{MIF,} 500 \mu \mathrm{M}$ & - \\
4 & - & $\mathrm{MIF}, 160 \mu \mathrm{M}$ \\
4 & $10 \mu \mathrm{l} \mathrm{BDNF}$ & - \\
4 & $10 \mu \mathrm{MIF}, 500 \mu \mathrm{M}$ & $\mathrm{BDNF}$ \\
4 & - & - \\
\hline
\end{tabular}

the retinal surfacc. Becausc microglia show a staggered, bilaminated distribution at late stages of degeneration (Thanos et al., 1992), it was essential to measure the microglia within both layers, namely, within the ganglion cell and within the deeper inner plexiform layers. Statistical analysis of the data obtained for each interval after axotomy was performed with the two-tailed Student's $t$ test. The densities of cells throughout the work are presented as means \pm SD of all fields measured from each experimental group.

\section{Results}

\section{Retrograde labeling of ganglion and microglial cells in} untreated rats

Deposition of the fluorescent dye 4Di-10ASP at the stump of the transected optic nerve or into the superior colliculus (SC) of control rats resulted in fast labeling of the ganglion cell bodies and dendrites when the retinas were examined $2 \mathrm{~d}$ (labeled from optic nerve, Fig. $1 a$ ) to $4 \mathrm{~d}$ (labeled from the SC) later. In control animals that did not receive injection of drugs and in those that received injection of $10 \mu 1$ phosphate buffer, labeling from the SC or optic nerve resulted in retrograde staining of $1780 \pm 240$ cells $/ \mathrm{mm}^{2}$ (12 rats), which approaches the density of ganglion cells determined with histological methods over the total surface of the rat retina (Perry, 1979). When the animals were killed at later stages after axotomy and labeling from the optic nerve, the ganglion cells were still intensely labeled 12 months later, indicating a long-term persistence of the dye within the axotomized and surviving neurons. Because axotomy causes a protracted degeneration of ganglion cells, the densities of these cells declined as expected with time elapsed after optic nerve transection (Fig. 1b,c,d) to approximately $360 \pm 48$ labeled cells/ $\mathrm{mm}^{2}$ at the end of the second, and to about $10 \pm 3$ labeled cells/ $\mathrm{mm}^{2}$ at the end of the sixth week after lesion (Fig. 2). Very few ganglion cells ( $<50$ per retina) were present and still labeled at the twelfth month after optic nerve transection (data not shown).

In conjunction with the course of ganglion cell disappearance, non-neuronal cells (Figs. $1 b-d, 2 B$ ), identified with the monoclonal antibody to the complement factor 3 receptor OX 42 (Hickey and Kimura, 1988; Ling et al., 1990; Thanos et al., 1992) and with the negative staining for glial fibrillary acidic protein (GFAP) as nonmacroglial cells (Thanos et al., 1992), first appeared in the optic fiber layer and ganglion cell layer on the eighth day after lesion, and their density increased in the GCL with time elapsed from lesion to peak at $14 \mathrm{~d}$ (Fig. 2B), and to decline to $350 \pm 25$ cells $/ \mathrm{mm}^{2} 4-6$ weeks after optic nerve transection (Fig. $2 B$ ). This microglial density remained stable until the fourth month and continuously declined from 4 to 12 months after lesion and labeling (data not shown). At all times of examination after optic nerve transection, microglial cells displayed a strong territorial arrangement within the ganglion cell (Fig. $1 b-d$ ) and inner plexiform layers, and a staggered, 

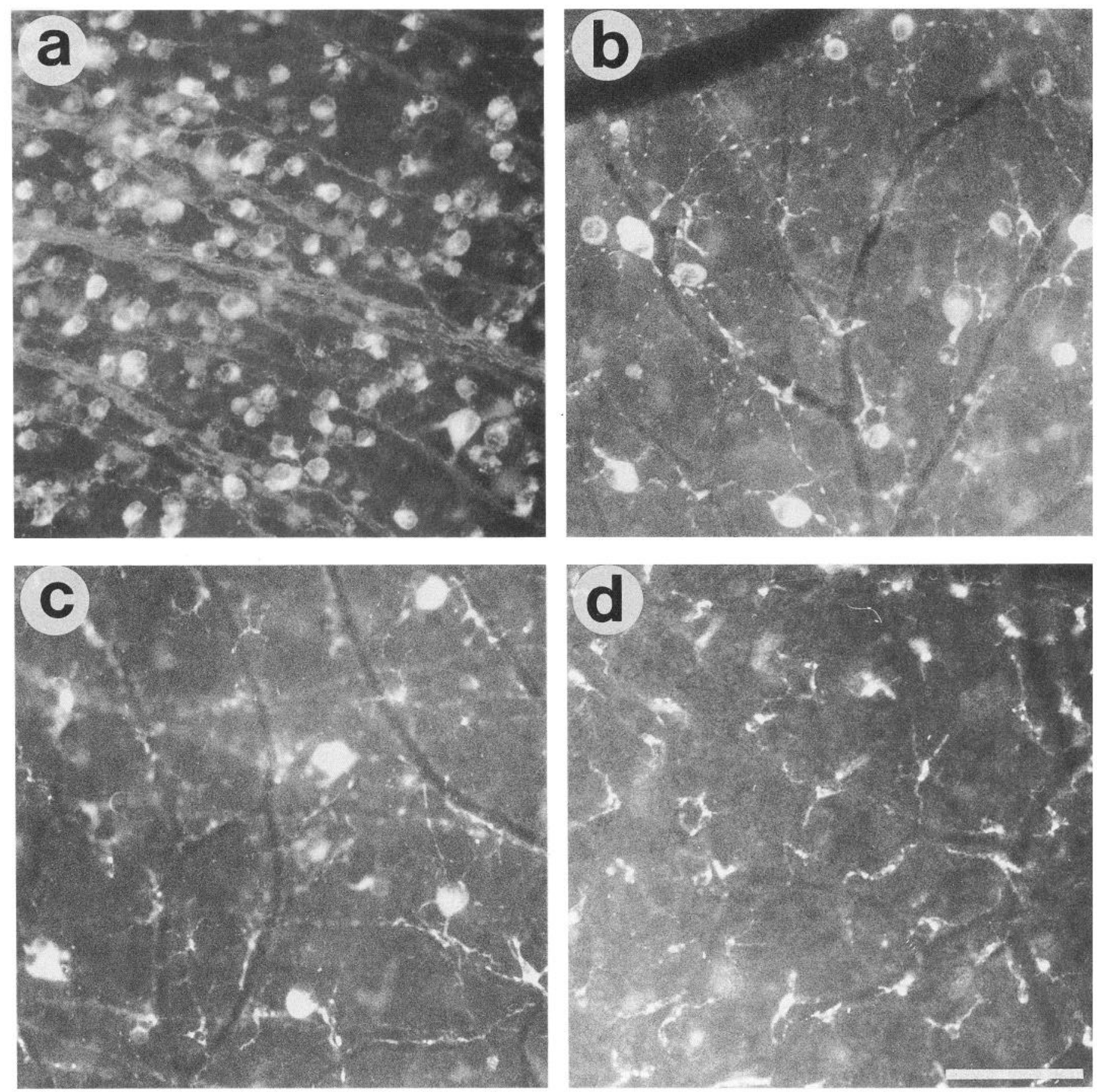

Figure 1. Fluorescence micrographs showing the progress of degeneration in the axotomized adult retina when viewed as whole-mount. $a$, Only retrogradely labeled ganglion cells can be seen in the retina $2 \mathrm{~d}$ after axotomy and deposition of 4Di-10ASP into the optic nerve stump. $b$, Two weeks after axotomy and labeling, fewer ganglion cells (large cell bodies) and, in addition, labeled microglial cells (small ramifying cells) can be seen preferentially along and contacting the blood capillaries. $c$, Further decrease and disappearance of ganglion cells is accompanied by increase of the microglial cell population 4 weeks after axotomy. $d$, Virtually no ganglion cells and territorially distributed microglial cells can be observed at the end of the sixth week after axotomy. Scale bar, $100 \mu \mathrm{m}$.

bilaminated distribution within the two layers (Thanos et al., 1992). Morphologically, microglial cells were small cells with elaborate ramifications within the retinal tissue (Fig. 1) and they almost always contacted blood capillaries with their branches, as is best visible in Figure $1 b-d$.

\section{Effects of MSF and MIF}

Microglial cells are bone marrow derived (del Rio Hortega, 1932; Hickey and Kimura, 1988; Perry and Gordon, 1988) and share some features in common with peripheral macrophages (Hickey and Kimura, 1988; Ling et al., 1990). It was therefore expected that they may be the targets of drugs directed to macrophages. One of the favorable substances that are natural stimulators of macrophages is the tetrapeptide tuftsin (Thr-Lys-ProArg), here referred to as MSF, which is naturally produced by cleavage of the human IgG by an endoprotease (Wagle et al., 1989). The tetrapeptide penetrated the cells and was found within the cytoplasmic fraction in polymorphonuclear leucocytes, 


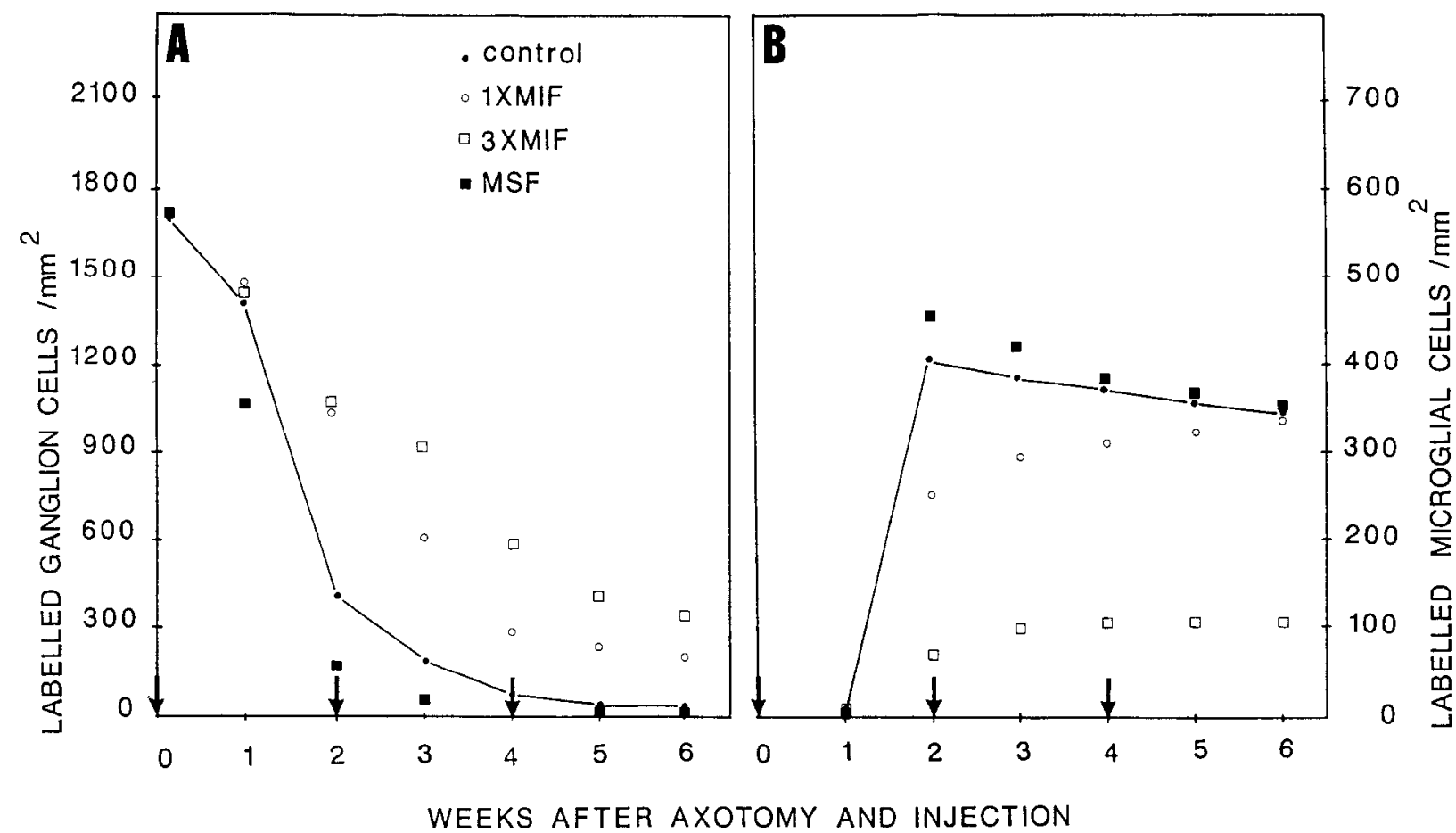

Figure 2. Graphs corroborating the course of ganglion cell degradation and microglial labeling under the experimental conditions reported in the present work. $A$, The course of ganglion cell decrease (continuous line) could be modified with MSF and MIF. MSF resulted in faster disappearance of labeled ganglion cells. Single injection of MIF at the time of axotomy resulted in increased populations of labeled ganglion cells, whereas repetitive injections of the substance (indicated with arrows at 2 and 4 weeks after axotomy) further delayed the disappearance of ganglion cells. $B$, The rise of microglial labeling seen in untreated retinas (continuous line) could be increased with injection of MSF, whereas MIF significantly delayed the labeling of microglial cells.

but translocated into the nucleus of human monocytes (Wagle et al., 1989). Retinas treated with MSF showed faster ganglion cell degradation and elevation of the number of labeled microglial cells than control retinas (Fig. 2). Typically, the numbers of ganglion cell bodies were significantly reduced below those of untreated controls 2-6 weeks after ON transection and the numbers of labeled microglial cells were higher than in controls, especially between the second and fourth weeks after axotomy and treatment (Fig. 2A,B).

Single injection of the tripeptide MIF (Thr-Lys-Pro) during the axotomy revealed opposite effects to those described for MSF: at the end of the second week after axotomy, there was a threefold increase in the number of surviving ganglion cells (Fig. $2 A$ ) and a decrease in the number of microglial cells (Fig. $2 B$ ). These effects persisted throughout the time of examination, six weeks after axotomy (Fig. $2 A, B$ ). Repetitive injections of 10 $\mu \mathrm{l}$ MIF, at the end of the second and at the end of the fourth weeks after axotomy, resulted in a further delay of ganglion cell degradation (Fig. $2 A$ ) and labeling of microglial cells (compared to retinas with single injections, Fig. $2 B$ ). Figure 3 shows the morphological images obtained from retinas at the end of the sixth week. Axotomy and labeling without any treatment resulted in regular labeling of microglial cells with very few ganglion cell bodies (Fig. $3 A$ ). Single injection of MIF resulted in marked increase of ganglion cell bodies and decrease of microglial cells (Fig. 3B), whereas triple injection of MIF led to dramatic effects on both ganglion and microglial cell numbers as shown in the two retinas presented in Figure $3, C$ and $D$.

To characterize further the target cells of MIF activity, the substance was injected into the eye of four animals at the fourth week after axotomy and labeling. Examination of the retinal whole-mounts one week ( 2 animals) and two weeks ( 2 animals) later revealed differences in the morphologies of microglial cclls compared with untreated retinas. The ramifications displayed in normal microglial cells (Fig. $4 a$ ) were virtually absent (Fig. $4 b$ ), indicating that the MIF at least affects the morphology and, presumably, the metabolism and function of these cells. No morphological changes in the microglial cell population were observed with all other substances tested so far.

\section{Viability of ganglion cells in vivo and axonal regeneration within transplanted peripheral nerve segments}

The appearance of fluorescent ganglion cell bodies alone does not suffice to deduce the presence of viable, functional neurons, because dead but nonphagocytosed somata may have been included in the evaluation. Therefore it was essential to confirm vital functions of the additional ganglion cells obtained with treatment of the retinas with either substance. Three traits of ganglion cells were selceted to prove their vital status: their ability to grow axons in vivo, the ability of these axons to transport substances retrogradely, and the ability of explanted pretreated retinas to regrow their axons in organ cultures.

The combined treatment of axotomized retinas with MIF and simultaneous transplantation of sciatic nerve pieces (Vidal-Sanz et al., 1987) resulted in massive ingrowth of axons into the transplant. The images in Figure $5 a-d$ illustrate that after deposition of the fluorescent dye 4Di-10ASP into the transplant 4 weeks after axotomy (position between the arrows in Fig. $5 b$ ), treatment with MIF, and grafting, the entire retinal eccentricity is covered by retrogradely filled ganglion cells (Fig. $5 a$ ). Ganglion cell bodies of the various sizes and morphologies were regularly distributed both within the central (Fig. $5 c$ ) and within the pe- 

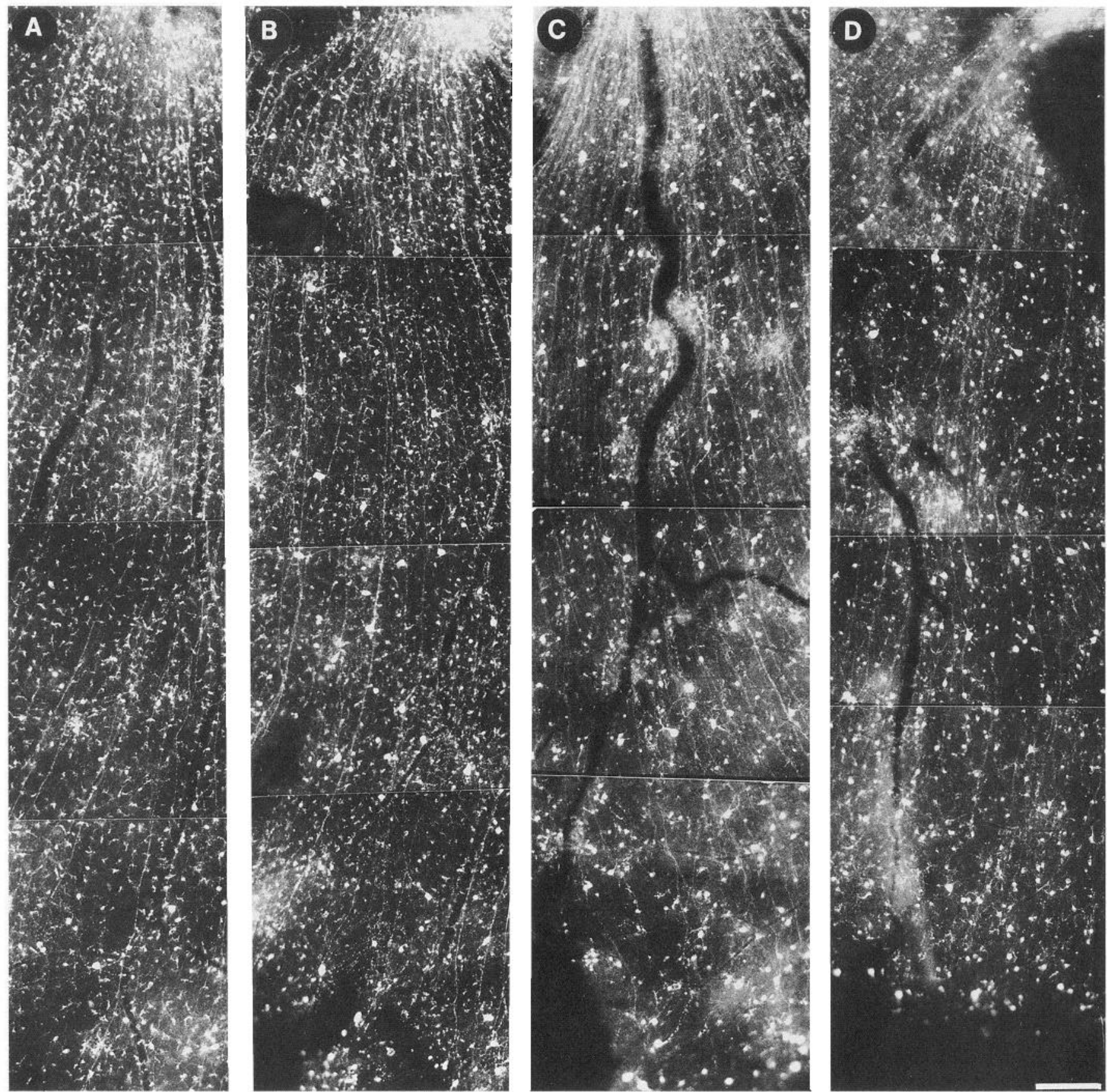

Figure 3. Low-power photomicrographs from whole-mounted retinas showing the distribution of microglial cells and ganglion cells after axotomy and deposition of 4Di-10ASP into the optic nerve stump. The upper edge of each montage represents the optic nerve head, and the bottom edge, the most peripheral edge of the retina, the ora serrata. Small, star-like cells, as best visible in $A$, are microglial cells, whereas cells with larger, spherical to oval perikarya represent ganglion cells. All retinas were dissected and examined 6 weeks after axotomy and labeling from the optic nerve. $A$, Control retina with the typical regular distribution of microglial cells and very few ganglion cells. $B$, The same region of a retina that received a single injection of MIF during axotomy and deposition of 4Di-10ASP at the optic nerve stump. There is a marked increase of labeled ganglion cells and decrease of microglial cells. $C$ and $D$, Two retinas that received triple injections of MIF at time of axotomy, at day 14 and at day 28 after axotomy and labeling. There is a dramatic increase in the numbers of ganglion cells and decrease in the numbers of microglial cells. In addition, microglial cell morphology is changed from the star-like type (as shown in $A$ ) to an oval type (compare with Fig. 4). Scale bar, $100 \mu \mathrm{m}$.

ripheral surface of the retina (Fig. $5 d$ ). The complete delineation of ganglion cell bodies and dendrites, in particular also in the most peripheral portion of the retina (Fig. 5d), is an index of intact axonal and dendritic transport.

The quantitative analysis of the retinas treated with various substances and of those that were only axotomized is presented in Figure 6. To label retrogradely the population of all axotomyresistant and thus surviving ganglion cells, they were stained from the site of junction between the ocular stump of the transected optic nerve and the peripheral nerve graft. To label regenerating ganglion cells, on the other hand, the fluorescent dye was deposited at a distance $12-14 \mathrm{~mm}$ from the $\mathrm{ON} /$ peripheral 

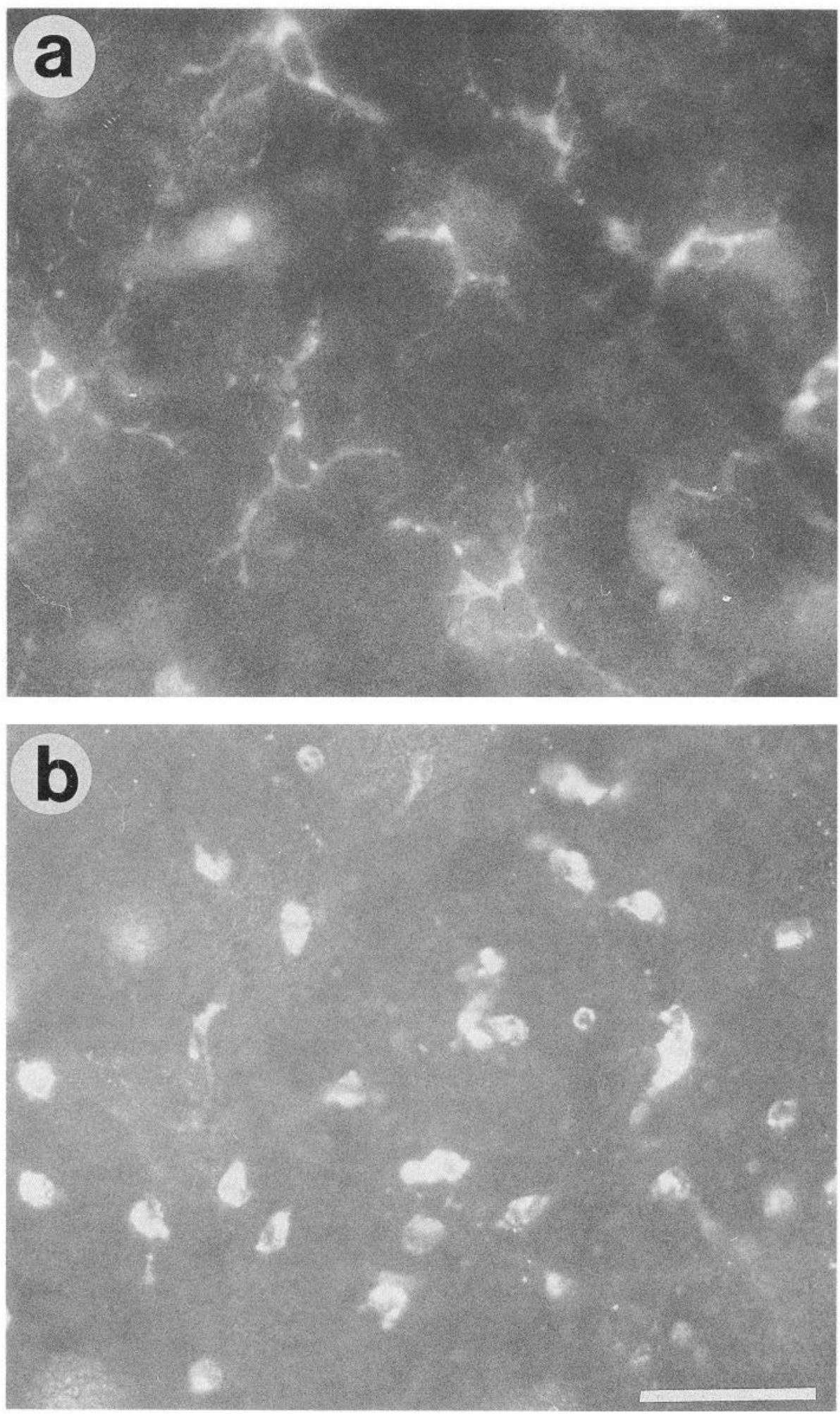

Figure 4. Effects of MIF on the morphology of microglial cells. $a$, Micrograph from the periphery of a wholemounted control retina that received 4Di-10ASP during axotomy and was examined $42 \mathrm{~d}$ later. Microglial cells appear well ramified with the dye distributed within the cytoplasm and branches. The cell nuclei remained unlabeled. $b$, This retina received axotomy, labeling with 4Di-10ASP during axotomy, and injection of MIF at day 28 and was examined at day 42 . The prelabeled microglial cells obviously retracted most of their ramifications and had oval to spherical shapes. The density of microglial cells in $b$ is higher than in $a$ because of the different retinal eccentricities of the images. Scale bar, 50 $\mu \mathrm{m}$. nerve graft anastomosis. Compared to the density of surviving ganglion cells in the axotomized control retina $(5.5 \%$ of the population that can be labeled with 4Di-10ASP in the normal retina), single or double injection of MIF $(16.8 \%$ and $33.7 \%$, respectively) dramatically elevated the numbers of viable ganglion cells. The highest efficacy of rescuing ganglion cells was observed after double injection of MIF $\left(600 \pm 42\right.$ cells $/ \mathrm{mm}^{2}$, i.e., about $33.7 \%$ of the normal population). Not all cells that survived after MIF treatment and peripheral nerve grafting extended axons into the transplanted nerve $(17.1 \%$ regenerating in comparison to $35.9 \%$ surviving neurons). Compared to the number of ganglion cells with regenerated axons in sciatic nerve transplants that were obtained without any pharmacological treatment (Fig. 6), injection of MIF during the procedure of 

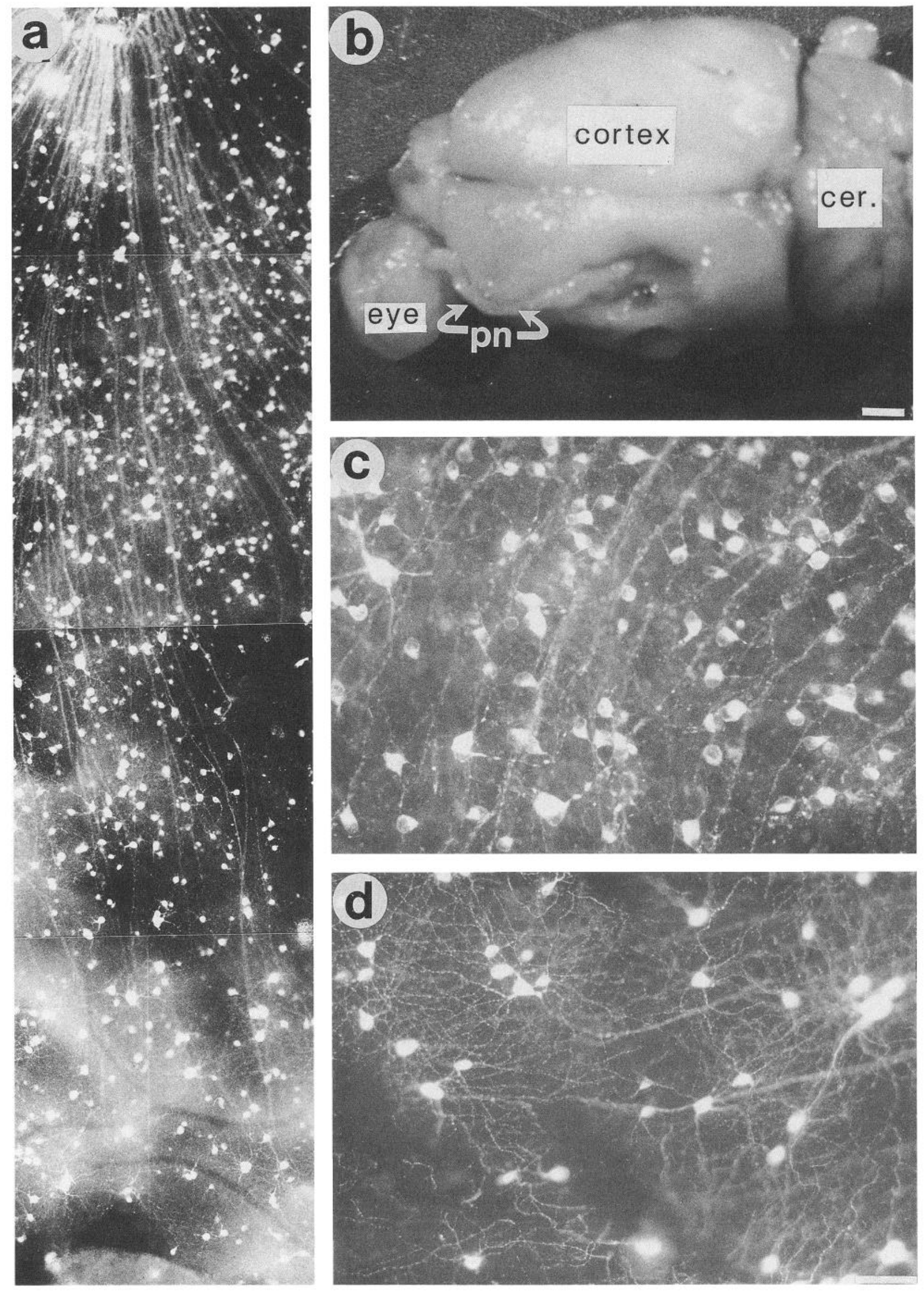
axotomy and grafting doubled the number of regenerating axons within the peripheral nerve graft.

\section{Ability of ganglion cells to regenerate axons in vitro}

To assess further whether growth properties of neurons are influenced by the presence of the various substances injected into the axotomized eye, retinal explants were prepared 1 week after optic nerve transection and intravitreal injections and cultured in a chemically defined S4 medium containing no serum or neurotrophic agents (Thanos et al., 1989). The rationale for using the $\mathrm{S} 4$ medium was that this medium proved to be the most suitable for culturing explants obtained from adult retina (Thanos et al., 1989). To quantify the effect of MIF on outgrowth of axons, and to compare this effect with that of neurotrophic factors, retinal explants were also cultured in the presence of bFGF, which has been shown to be a neurotrophic factor for adult ganglion cells (Sievers et al., 1987). An additional group of explants were cultured in the presence of BDNF (Barde et al., 1982), which has been shown to have neuritogenic effects on adult ganglion cells in vitro (Thanos et al., 1989). Evaluation of the axonal growth $2 \mathrm{~d}$ after explantation revealed the following results: placement of the explants in the $\mathrm{S} 4$ medium resulted in a basic outgrowth ( $24 \pm 8$ neurites/explant, $n=34$ explants) that could be enhanced to $75 \pm 18$ neurites/explant $(n=32$ explants) with bFGF. BDNF had significant effects on outgrowth of axons ( $230 \pm 28$ axons/explant, $n=32)$, whereas in the controls with MIF substituted in culture there was only slight enhancement of axonal growth (70 \pm 9 neurites/explant, $n=$ 32). Injection of MIF during optic nerve crush in situ and subsequent explantation revealed significantly higher numbers of axons (542 \pm 50 neurites/explant, $n=32)$. It appeared from these experiments that injection of MIF protects ganglion cells from degradation and provides a higher population of cells for regeneration in vitro than observed in control retinas.

\section{Discussion}

The interruption of ganglion cell axons within the optic nerve of adult rats leads to a cascade of neuronal and environmental responses that culminate in the protracted depopulation of the retinal GCL. Degenerating ganglion cells are phagocytosed by retinal microglial cells, which become activated soon after injury and remove cell debris in a strong chrono-topological sequence that parallels the course of the neuronal degradation (Thanos, 1991; Thanos et al., 1992). The principal new finding of the present study was that the activity of these microglial cells can be influenced to result in retardation of the degenerative events initiated by the axotomy. This microglia-mediated reduction of ganglion cells following transection of the optic nerve, seems to be one of the major impediments to rescuing and reconnecting these neurons with central target cells in sufficient quantity and in a topographic fashion that would retrieve physiological function. Thus, understanding the mechanisms that contribute to the destruction of lesioned neurons, and developing strategies

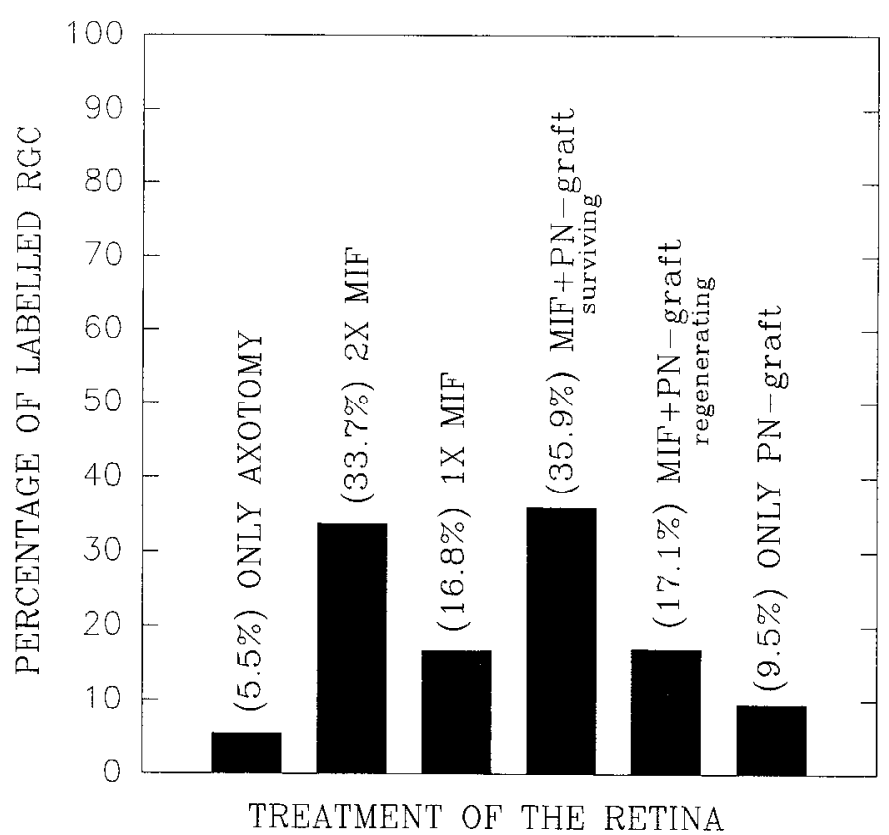

Figure 6. Quantification of the numbers of ganglion cells that survived axotomy under conditions tested in the present study. The population of ganglion cells that can be labeled in the normal retina (1780 \pm 240 cells $/ \mathrm{mm}^{2}$ ) was set at $100 \%$, and the surviving or regenerating populations of cells are presented as percentage of the normal population. All data represent measurements at $28 \mathrm{~d}$ after axotomy, peripheral nerve $(P N)$ grafting, and treatment of the retina with intravitreally injected substances. Labeling was performed $4 \mathrm{~d}$ prior to examination as described in Figure $5 b$. Each group comprises the measurements of three or four retinas with identical treatment. There is remarkable increase of axotomy-resistant ganglion cells in retinas treated with MIF $(16.8 \%$ after single and $33.7 \%$ after double injection). Highest numbers were determined in retinas injected with MIF and received peripheral nerve grafts. Of the surviving ganglion cells (35.9\%), about every second cell can regrow its axon into the peripheral nerve graft $(17.1 \%$ of the normal population). This is significantly different $(p<0.05)$ from the population of axons that grew into the peripheral nerve graft in untreated retinas $(9.5 \%)$.

for manipulating these mechanisms to rescue cells from degradation, will help to achieve both goals, that of preventing cell death, and that of promoting axonal regeneration.

\section{The role of microglial cells in the axotomized retina}

There is increasing evidence that microglial cells as a major, uniformly distributed population of immunocompetent cells within the brain (Perry and Gordon, 1988; Streit et al., 1989; Giulian, 1990; Giulian et al., 1990) are related to a number of regressive events in the brain. These include neurodegenerative diseases like Alzheimer's disease (Gras et al., 1990), multiple sclerosis (Boyle and McGeer, 1990), and viral infections in which microglial cells seem to be the principal targets of the viruses (Giulian et al., 1990). Besides the coincident appearance of microglial cells at sites of naturally dying neurons (Schnitzer and

Figure 5. Regeneration of MIF-treated GC in vivo. $a$ and $b$, The flat-mounted retina of an animal that received a peripheral nerve graft ( $p n$ ), intravitreal injection of MIF during axotomy, 4Di-10ASP in the peripheral nerve graft position indicated with the two arrowtips in $b$ at day 28 and examination of the retina at day 42 after axotomy and grafting. As shown in the low-power micrograph in $a$, which includes a retinal sector from the optic nerve head (top) to ora serrata (bottom), there is a dense population of fluorescent and thus regenerating ganglion cells distributed throughout the retinal eccentricity. The density of ganglion cells in this retina was $366 \pm 45 \mathrm{cells} / \mathrm{mm}^{2}$, indicating a high incidence of regeneration by using this combined procedure of preventing degradation and providing permissive environment for growth of axons. $c$ and $d$, Higher magnifications from two regions within the central $(c)$ and peripheral $(d)$ retina showing the morphologies of the ganglion cell bodies and, in particular in the periphery, of their dendritic ramifications, which are completely outlined with the fluorescent dye. cer., cerebellum. Scale bars, $100 \mu \mathrm{m}$. 
Scherer, 1990; Thanos, 1991; Milligan et al., 1992), or in lesioned areas of the brain, there is evidence from both in vitro and in situ studies (for review, Giulian, 1990) that these cells contribute to the degradation of neurons by cytotoxic molecules whose nature and accurate characterization is a matter of ongoing studies.

Three findings of the present work especially strengthen this convergent opinion of the role of microglial cells during degradation of axotomized ganglion cells. (1) Microglial cells are selectively labeled with the fluorescent dye when prelabeled ganglion cells die. (2) More ganglion cells survive when the microglial cells are treated with the tripeptide MIF. (3) The process of ganglion cell degradation is faster when the retina is treated with the macrophage-stimulating tetrapeptide MSF.

One of the major implications of the present work was that pharmacological treatment of the microglial cells contributes to the retardation of neuronal degeneration. Combined specific transcellular tracing of the neurophagic microglial cells and manipulation of microglial activities in the retrogradely degenerating retina are best explained by the presence of highly specialized mechanisms that are initiated by axotomy and are devoted to the destruction of neurons. In concert, the interactions between microglial cells and their microenvironment including astrocytes and Müller cells (Bignami and Dahl, 1979) are probably also part of the cascade of responses. Microglialmacroglial interactions may involve astrocyte-activating molecules (Woodroofe et al., 1991), such as interleukines, which stimulate the astrocytes to proliferate (Giulian and Lachman, 1985; Giulian, 1987; Perry and Gordon, 1988) and to become hypertrophic (Barron et al., 1990). Among the interleukines that are candidates for astrocyte stimulation, IL- 1 appears to play a key role. It is expressed in activated brain microglial cells and regulates axotomy-induced astrocyte proliferation (Fagan and Gage, 1990). Activation of microglial cells after axotomy leads to expression of antigens from the myelomonocytic lineage as recognized by monoclonal antibodies ED1 and ED3 (Graeber et al., 1990). In neurodegenerative diseases such as multiple sclerosis and Alzhcimcr's disease, microglial cells are ultrastructurally very closely associated with altered neurons and neuroglia and they express type I (HLA-A,B,C) and type II (HLADR) MHC antigens (Gras et al., 1990; Tooyama et al., 1990), as indices of their involvement in multiple processes of degeneration with different etiologies. The close association of microglial ramifications to the perivascular glia limitans (Lassman et al., 1991), and the expression of various antigens (common leukocyte antigen, complement receptor 3 , and $\mathrm{MHC}$ antigens) as a response to intravenous injection of $\gamma$-interferon or tumor necrosis factor also suggest an interplay between resident microglial processes and components of the blood-brain barrier (Lassman et al., 1991). This structural association to the retinal capillaries was also consistently observed throughout the present investigation. Recent studies that examined the expression of macrophage sialic acid-binding receptor on resident microglia lend further support to the idea that microglia permanently communicates with the plasma and that its phenotype is regulated by the presence of the blood-brain barrier (Perry et al., 1992).

David et al. (1990) investigated the localization of ED1-positive mononuclear macrophages within the lesioned rat optic nerve and assumed that these cells remove the optic nerve myelin during the first $5 \mathrm{~d}$ after axotomy. This observation, which confirmed similar results of Stoll et al. (1989), prompted the investigators to explant embryonic chick dorsal root ganglia on optic nerve sections incubated with mononuclear brain macrophages. It was observed that this treatment changed the nonpermissive sections to become permissive substrata for fiber outgrowth (David et al., 1990). The authors assumed that the macrophages (collected in nitrocellulose filters) were derived from the peripheral circulation and that these cells may be different in their response from resident brain microglial cells (Milligan et al., 1992). The present data also show that if ganglion cells have the opportunity to regrow their axons, as occurs in the transplantation and in the organ culture experiments, they are not attacked by intraretinal microglial cells or by co-explanted macrophages. This, as the results of David et al. (1990), is in conformity with the tested hypothesis that the autodestructive cascade is initiated only if the ganglion cells are inhibited to regrow their axons as occurs in their naturally lesioned optic nerve environment. The scavenger role of microglial cells may not be the only function of these cells within the lesioned brain, and the cells may exert different functions within the white matter such as the optic nerve and within areas with perikarya, as the retina.

\section{Effects of MSF and MIF}

Axotomized ganglion cells died more rapidly in retinas treated with the tetrapeptide MSF, which is part of the human $\operatorname{IgG}$ and is normally produced by cleavage of the molecule by a splenic endoxycarbopeptidase (Fridkin and Najjar, 1989; Kraus-Berthier et al., 1991). The active tetrapeptide, also known as tuftsin, binds to a receptor of two subunits of approximately $66 \mathrm{kDa}$ and $57 \mathrm{kDa}$ on macrophages (Bump et al., 1990). MSF exerts a broad spectrum of specific activities, which include potentiation of cell functions like phagocytosis, motility, and immunogenic response (Fridkin and Najjar, 1989; Sorokin et al., 1989). It is therefore not surprising that it also activates the phagocytotic microglial cells in the treated retinas, although its mode of action after MSF binding remains to be determined. The demonstration that enhancement of microglial cell numbers was paralleled by faster degradation of ganglion cells is consistent with the assumption that the tetrapeptide activates the microglial cells. The exact side of MSF action remains unknown, although there is evidence for its binding on receptors and translocation into the nucleus of human monocytes (Wagle et al., 1989). MSF has been shown to effect several CNS functions such as the release of hypothalamic hormone, short-term antinociception, increased blood pressure, and suppression of food uptake (for review, see Plata-Salomon, 1989). Systemic administration of MSF induces IL-1 release (Fauci et al., 1987). One of the MSF effects on microglial cells in vitro seems to be the production of IL-1 (Spirer et al., 1989), a cytokine that efficiently stimulates astrocytes (literature cited in Fagan and Gage, 1990). Both observations lend support to the present study, which showed stimulation of microglial cells, though the mechanism of the MSF activity still remains to be analyzed.

The opposite effects of the tripeptide MIF, which is related to MSF but one amino acid shorter, correspond to its ability to inhibit cells of monocytic origin (Auriault et al., 1983; Sorokin et al., 1989). As suggested for the first time in the present work, the tripeptide may modulate the metabolic status of microglial cells. This effect-its correlate may be seen in the morphological alterations of microglia - is probably crucial for the activity of these cells. MIF treatment also results in reduction of the speed of microglial labeling via ingestion of 4Di-10ASP-prelabeled 
ganglion cell membranes and in reduction of the speed of ganglion cell degradation. The metabolic effects of MIF on microglial cells seem to be crucial because morphologically they culminate in the retraction of microglial branches. The effects are obviously transient, as blocked microglial cell numbers approach normal values about six weeks after single, but not after repetitive, injections (see Fig. 2). This conforms with the parallel observations on ganglion cell death, which is retarded only for a few weeks after axotomy. Both effects, combined with the morphological alterations that microglial cells undergo after treatment, strongly indicate that microglial cells are involved in the destructive cascade devoted to eliminating the axotomized ganglion cells. The fact that repetitive injections of MIF can further delay the process of neuronal destruction lends additional support to this hypothesis. Although the cellular site of MIF action remains to be unraveled, the tripeptide is likely using the MSF receptors (Bump et al., 1990) or other membrane receptors that will then produce the opposite effect from MSF within the microglial cells.

The retention of more viable ganglion cells that then could regrow their axons in vivo and in vitro resulted under treatment of MIF. The higher incidence of regeneration in the presence of MIF in the transplantation paradigm implies that this strategy is one of the possible ways to obtain larger populations of regenerating neurons. In the present study, the density of ganglion cells whose axons penetrated the peripheral nerve grafts was larger than those reported in former studies (Politis and Spencer, 1986; Vidal-Sanz et al., 1987; Villegas-Perez et al., 1988). When viewed on the flat-mounted retina (compare with Fig. 6), the uniformly distributed ganglion cells of different sizes cover the retinal surface with their dendrites. It remains to be seen whether this density of ganglion cells is sufficient for a retinotopic reconnection of the retina with central targets, and in particular with the SC (S. Thanos, J. Mey, and M. Wild, unpublished observations). The fact that retinal axons form well-differentiated synapses within the adult retinoreceptive areas (Carter et al., 1989) and that these synapses respond to light stimulation (Keirstead et al., 1989) may help to evaluate functional significance of the recreated connections. The critical role of the microglial cells in this system seems to consist in its effective response soon after nerve lesion. The opportunity, however, for neurons to reelongate their axons into peripheral nerve grafts seems to protect them from degradation, presumably because axonal growth is a functional status. The process of growth is associated with axonal transport and may result in reduced accumulation of newly synthesized material within the perikaryon, in prevention of chromatolysis, and ultimately in suppression of the autodestructive cascade of cell death (Lieberman, 1971). It will therefore be of crucial relevance for the process of regeneration to suppress the microglial, and presumably also other regressive activities, to provide high populations of ganglion cells that can be recruited to reestablish central connections. In addition, the exploration of the sequence of interdependent events that are initiated by axotomy and retrograde transport of axotomy-induced signals (Singer et al., 1982) is of crucial importance in determining their reversibility, which might be beneficial for the lesioned neurons.

\section{References}

Auriault C, Joseph M, Tartar A, Capron A (1983) Characterization and synthesis of a macrophage inhibitory peptide from the second constant domain of human immunoglobulin G. FEBS Lett 153:1115.

Barde YA, Edgar D, Thoenen H (1982) Purification of a new neurotrophic factor from mammalian brain. EMBO J 1:549-553.

Barron KD, Dentinger MP, Lohel G, Easton SK, Mankes R (1986) Qualitative and ultrastructural observations on retinal ganglion cell layer of rat after intraorbital nerve crush. J Neurocytol 15:345-362.

Barron KD, Marciano FF, Amundson R, Mankes R (1990) Perineuronal glial responses after axotomy of central and peripheral axons. A comparison. Brain Res 523:219-229.

Bignami A, Dahl D (1979) The radial glia of Müller and their response to injury. An immunofluorescence study with antibodies to the glial fibrillary acidic (GFA) protein. Exp Eye Res 28:63-69.

Boyle EA, McGeer PL (1990) Cellular immune response in multiple sclerosis plaques. Am J Pathol 137:575-584.

Bump NJ, Najjar VA, Reichler J (1990) The characteristics of purified HL 60 tuftsin receptors. Mol Cell Biochem 92:77-84.

Cammermeyer J (1970) The life history of the microglia cell: a light microscopic study. In: Neurosciences research, Vol 3 (Ehrenpreis S, Solnitzky OC, eds), pp 44-129. New York: Academic.

Carmignoto G, Maffei L, Candeo P, Canella R, Comelli C (1989) Effect of NGF on the survival of rat retinal ganglion cells following optic nerve section. J Neurosci 9:1263-1272.

Carter D, Bray GM, Aguayo AJ (1989) Regencrated ganglion cell axons can form well-differentiated synapses in the superior colliculus of adult hamsters. J Neurosci 9:4042-4050.

David S, Bouchard C, Tsatas O, Giftochristos N (1990) Macrophages can modify the nonpermissive nature of the adult mammalian central nervous system. Neurons 5:463-469.

del Rio-Hortega P (1932) Microglia. In: Cytology and cellular pathology of the nervous system (Penfield W, ed), pp 482-534. New York: Hoeber.

Faden AI, Salzman S (1992) Pharmacological strategies in CNS trauma. Trends Pharmacol Sci 13:29-35.

Fagan AM, Gage FH (1990) Cholinergic sprouting in the hippocampus: a proposed role for IL-1. Exp Neurol 110:105-120.

Fauci AS, Rosenberg SA, Sherwin SA, Dinarello GA, Longo DL, Lane HC (1987) Immunomodulators in clinical medicine. Ann Int Med $106: 421-433$.

Fridkin M, Najjar VA (1989) Tuftsin: its chemistry, biology and clinical potential. Crit Rev Biochem Mol Biol 24:1-40.

Giulian D (1987) Ameboid microglia as effectors of inflammation in the central nervous system. J Neurosci Res 18:155-171.

Giulian D (1990) Microglia and tissue damage in the central nervous system. In: Differentiation and functioning of glial cells (Levi G, ed), pp 379-389. New York: Liss.

Giulian, D, Lachman LB (1985) Interleukin-1 stimulates astroglial proliferation after brain injury. Science 228:497-499.

Giulian D, Chen J, Ingeman JE, George JK, Noponen M (1989) The role of mononuclear phagocytes in wound-healing after traumatic injury to adult mammalian brain. J Neurosci 9:4416-4429.

Giulian D, Vaca K, Noonan CA (1990) Secretion of ncurotoxins by mononuclear phagocytes infected with HIV-1. Science 250:1593-1596.

Graeber MB, Streit W, Kiefer R, Schoen SW, Kreutzberg GW (1990) New expression of myelomonocytic antigens by microglia and perivascular cells following lethal motor neuron injury. J Neuroimmunol 27:121-132.

Grafstein B, Ingoglia NA (1982) Intracranial transection of the optic nerve in adult mice: preliminary observations. Exp Neurol 76:318330.

Gras P, Kawai M, Siedlak S, Mulvihill P, Gambetti P, Lowery D, Dewhitt-Gonzalez P, Greeberg B, Perry G (1990) Neuronal and microglial involvement in beta-amyloid protein deposition in Alzheimer's disease. Am J Pathol 137:141-146.

Hickey WF, Kimura H (1988) Perivascular microglial cells of the CNS are bonc-derived and present in antigen in vivo. Science 239:290292.

James GR (1933) Degeneration of ganglion cell following axonal injury. Arch Ophthalmol (Copenh) 9:338-343.

Keirstead SA, Rasminsky M, Fukuda Y, Carter DA, Aguayo AJ, VidalSanz M (1989) Electrophysiological responses in hamster superior colliculus evoked by regenerating retinal axons. Science 246:255-257.

Kraus-Berthier L, Ferry G, Compe-Perez V, Visalli M, Remond G, Vincent M, Boutin JA (1991) Approaches to some biochemical mechanisms of action of tuftsin and analogues. Biochem Pharmacol 41:1411-1418. 
Lassmann H, Zimprich F, Vass K, Hickey WF (1991) Microglial cells are component of the perivascular glia limitans. J Neurosci Res 28: $236-243$.

Lieberman AR (1971) The axon reaction: a review of the principal features of perikaryal responses to axon injury. Int Rev Neurobiol $14: 49-124$

Ling EA, Kaur LC, Yick TY, Wong WC (1990) Immunocytochemical localization of CR 3 complement receptors with OX-42 in amoeboid microglia in postnatal rats. Anat Embryol (Berl) 182:481-486.

Milligan CE, Levitt P, Cunningham TJ (1992) Brain macrophages and microglia respond differently to lesions of the developing and adult visual system. J Comp Neurol 314:136-146.

Naim JO, Hinshaw JR, van Oss CJ (1989) The lack of antigenicity of tuftsin: a naturally occurring phagocytosis stimulating tetrapeptide. Immunol Invest 18:817-824.

Perry VH (1979) The ganglion cell layer in the retina of the rat. Proc R Soc Lond [Biol] 204:363-375.

Perry VH, Gordon S (1988) Macrophages and microglia in the nervous system. Trends Neurosci 11:273-277.

Perry VH, Crocker PR, Gordon S (1992) The blood brain barrier regulates the expression of a macrophage sialic acid-binding receptor on microglia. J Cell Sci 101:201-207.

Plata-Salaman CR (1989) Immunoregulators in the nervous system. Neurosci Biobehav Rev 15:185-215.

Politis MJ, Spencer PS (1986) Regeneration of rat optic axons into peripheral nerve grafts. Exp Neurol 91:52-59.

Ramon y Cajal (1928) Degeneration and regeneration of the nervous system (May RM, trans). London: University Press.

Schnitzer J, Scherer J (1990) Microglial cell responses in the rabbit retina following transection of the optic nerve. J Comp Neurol 302: 779-791.

Schwab ME, Caroni P (1988) Oligodendrocytes and CNS myelin are non-permissive for neurite growth and fibroblast spreading in vitro. J Neurosci 8:2381-2393.

Sievers J, Hausmann B, Unsicker K, Rerry M (1987) Fibroblast growth factors promote the survival of adult rat retinal ganglion cells after transection of the optic nerve. Neurosci Lett 76:157-162.

Singer PA, Mehler S, Fernandez HL (1982) Blockade of retrograde axonal transport delays the onset of metabolic and morphologic changes induced by axotomy. J Neurosci 2:1299-1306.

Sorokin SP, Hoyt Jr RF, McNally NA (1989) Nonimmune-mediated phagocytosis by "premedullary" lung macrophages: effects of concanavallin A, tuftsin and macrophage inhibitory peptide. Anat Rec 223:55-61.

Spirer Z, Zakuth V, Tzehoval E, Dagan S, Fridkin M, Golander A, Melamed I (1989) Tuftsin stimulates IL-1 production by human mononuclear cells, human spleen cells and mouse spleen cells in vitro. $\mathrm{J}$ Clin Lab Immunol 28:27-31.
Stoll G, Trapp BD, Griffin JW (1989) Macrophage function during Wallerian degeneration of the rat optic nerve: clearance of degenerating myelin and Ia expression. J Neurosci 9:2327-2335.

Streit WJ, Graeber MB, Kreutzberg GW (1989) Functional plasticity of microglia: a review. Glia 1:301-307.

Thanos S (1988) Alterations in the morphology of ganglion cell dendrites in the adult rat retina after optic nerve transection and grafting of peripheral nerve segments. Cell Tissue Res 259:599-609.

Thanos S (1991) The relationship of microglial cells to dying neurons during natural neuronal cell dcath and axotomy-induced degeneration. Eur J Neurosci 3:1189-1207.

Thanos S, Bähr M, Barde YA, Vanselow J (1989) Survival and axonal elongation of adult rat retinal ganglion cells. In vitro effects of lesioned sciatic nerve and brain derived-neurotrophic factor. Eur J Neurosci 1:19-26.

Thanos S, Pavlidis C, Mey J, Thiel HJ (1992) Specific transcellular staining of microglia in the adult rat after traumatic degeneration of carbocyanine-filled retinal ganglion cells. Exp Eye Res 54:377-391.

Tooyama I, Kimura H, Akiyama H, McGeer PL (1990) Reactive microglia express class I and class II major histocompatibility complex antigens in Alzheimer's disease. Brain Res 532:273-280.

Tzehoval E, Segal S, Stabinsky Y, Fridkin M, Spirer Z, Feldman M (1978) Tuftsin (an Ig-associated tetrapeptide) triggers the immunogenic function of macrophages: implications for activation of programmed cells. Proc Natl Acad Sci USA 75:3400-3404.

Vanselow J, Schwab ME, Thanos S (1990) Responses of regenerating rat retinal ganglion cell axons to contacts with central nervous myelin in vitro. Eur J Neurosci 2:121-125.

Vidal-Sanz M, Bray GM, Villegas-Perez MP, Thanos S, Aguayo AJ (1987) Axonal regeneration and synapse formation in the superior colliculus by retinal ganglion cells in the adult rat. J Neurosci 7:28942909.

Vidal-Sanz M, Bray GM, Aguayo AJ (1991) Regenerated synapses persist in the superior colliculus after regrowth of retinal ganglion cell axons. J Neurocytol 20:940-952.

Villegas-Perez MP, Vidal-Sanz M, Bray GM, Aguayo A (1988) Influences of peripheral nerve grafts on the survival and regrowth of axotomized retinal ganglion cclls in adult rats. J Neurosci 8:265-280.

Wagle JR, Ansevin AT, Dessens SE, Nishioka K (1989) Specific translocation of tuftsin (Thr-Lys-Prol-Arg), a natural immunomodulating peptide into the nuclei of human monocytes. Biochem Biophys Res Commun 159:1147-1153.

Woodroofe MN, Sarna GS, Wadhwa M, Hayes GM, Loughlin AJ, Tinker A, Cuzner ML (1991) Detection of interleukin- 1 and interleukin-6 in adult rat brain, following mechanical injury, by in vivo microdialysis: evidence of a role for microglia in cytokine production. I Neuroimmunol 33:227-236. 